\title{
The Afghanistan Papers: Decades of Deceit
}

In December 2019, The Washington Post released an in-depth report titled "At War With the Truth." "The report based its findings on a trove of internal documents from the Special Inspector General for Afghanistan Reconstruction (SIGAR) regarding the status of the U.S. government's war in Afghanistan. Among other things, the Afghanistan Papers highlighted that high-ranking U.S. leaders held the view that the war was unwinnable and took steps to keep this information from the American public and Congress. As John Sopko, the head of SIGAR put it, the Afghanistan Papers showed that "the American people have constantly been lied to."

This was consistent with prior warnings regarding deception by the U.S. government regarding the Afghanistan War. Over a decade ago, Lieutenant Colonel Daniel Davis, a veteran of the Afghanistan War, wrote the following:

Senior ranking US military leaders have so distorted the truth when communicating with the US Congress and American people in regards to conditions on the ground in Afghanistan that the truth has become unrecognizable. This deception has damaged America's credibility among both our allies and enemies, severely limiting our ability to reach a political solution to the war in Afghanistan. It has likely cost American taxpayers hundreds of billions of dollars Congress might not otherwise have appropriated had it known the truth, and our senior leaders' behavior has almost certainly extended the duration of this war. The single greatest penalty our Nation has suffered, however, has been that we have lost the blood, limbs and lives of tens of thousands of American Service Members with little to no gain to our country as a consequence of this deception. ${ }^{3}$

What Davis and the Afghanistan Papers highlight is the systematic use of propaganda by the U.S. government. Propaganda involves the dissemination of biased or false information to promote a political cause 
championed by the propagandist. Its purpose is to manipulate the beliefs of the recipients to align with the aims of the propagandist even if those goals are at odds with the interests of the target audience.

The purpose of this book is to explain how propaganda operates in democratic politics and why it matters for citizens. Our focus is on government-produced propaganda targeting the domestic populace within the United States in the post-9/I I period. We show that the U.S. government has purposefully provided partial and misleading information about the actual threats to the security of U.S. persons while contributing to a broader culture of militarism, which holds that a powerful military apparatus is necessary to protect and promote freedom and order at home and abroad. ${ }^{4}$

Government propaganda is a direct threat to freedom and liberty because it empowers a small political elite who wields awesome discretionary powers to shape policies while keeping citizens in the dark about the underlying realities and the array of alternative options available. In doing so, propaganda aims to shift the relationship between the citizenry and the state. Instead of the consent of the governed being the driving force behind the state's operations, private citizens are viewed as opposition that must be manipulated to achieve the propagandists' goals. As we will discuss, these issues are especially pertinent in matters of national security, where the government jealously guards its monopoly on privileged access to information. This monopoly on information enables those in power to present information to the public in a manner conducive to achieving their desired ends in the name of the "public interest."

As the Afghanistan Papers remind us, the dissemination of war-related propaganda by the U.S. government is alive and well. In what follows we explore how the government's propaganda machine operates and the threat it poses to a free society. 
M A N U F A C T U R I N G M I L I T A R I S M 
This page intentionally left blank 